\title{
Efficacy of chloral hydrate oral solution for sedation in pediatrics: a systematic review and meta-analysis
}

This article was published in the following Dove Press journal:

Drug Design, Development and Therapy

\author{
Zhe Chen ${ }^{1-3}$ \\ Mao $\operatorname{Lin}^{1-4}$ \\ Zongyao Huang ${ }^{1-4}$ \\ Linan Zeng ${ }^{1-3}$ \\ Liang Huang ${ }^{1-3}$ \\ Dan $\mathrm{Yu}^{3,5}$ \\ Lingli Zhang ${ }^{1-3}$
}

\begin{abstract}
'Department of Pharmacy, West China Second University Hospital, Sichuan University, Chengdu, People's Republic of China; ${ }^{2}$ Evidence-Based Pharmacy Center, West China Second University Hospital, Sichuan University, Chengdu, People's Republic of China; ${ }^{3}$ Key Laboratory of Birth Defects and Related Diseases of Women and Children, Sichuan University, Ministry of Education, Chengdu, People's Republic of China; ${ }^{4}$ West China School of Pharmacy, Sichuan University, Chengdu, People's Republic of China; ${ }^{5}$ Department of Pediatric, West China Second University Hospital, Sichuan University, Chengdu, People's Republic of China
\end{abstract}

Objective: Chloral hydrate $(\mathrm{CH})$, as a sedation agent, is widely used in children for diagnostic or therapeutic procedures. However, it has not come into the market and is currently only used as hospital preparation in China. This review aims to systematically evaluate the efficacy of $\mathrm{CH}$ in children of all age groups for sedation before medical procedures.

Materials and methods: Seven electronic databases and three clinical trial registry platforms were searched and the deadline was September 2018. Randomized controlled trials (RCTs) evaluating the efficacy of $\mathrm{CH}$ for sedation in children were included by two reviewers. The extracted information included success rate of sedation, sedation latency and sedation duration. The Cochrane risk of bias tool was applied to assess the risk of bias. The outcomes were analyzed by Review Manager 5.3 software and expressed as relative risks (RR) or Mean Difference (MD) with 95\% confidence interval (CI). Heterogeneity was assessed with I-squared $\left(\mathrm{I}^{2}\right)$ statistics.

Results: A total of 24 RCTs involving 3564 children of $\mathrm{CH}$ for sedation were included in the meta-analysis. Compared to placebo group, $\mathrm{CH}$ group had a significant increase in success rate of sedation when used for painless and painful procedure $(\mathrm{RR}=4.15,95 \% \mathrm{CI}$ $[1.21,14.24], \mathrm{P}=0.02 ; \mathrm{RR}=1.28,95 \%$ CI $[1.17,1.40], \mathrm{P}<0.01)$, which included 22 and 455 children for this analysis, respectively. Compared to midazolam group, $\mathrm{CH}$ group had a significant increase in success rate of sedation $\left(\mathrm{RR}=1.63,95 \% \mathrm{CI}[1.48,1.79], \mathrm{I}^{2}=0 \%\right.$, $\mathrm{P}<0.00001)$, sedation latency $\left(\mathrm{MD}=13.29,95 \% \mathrm{CI}[11.42,15.16], \mathrm{I}^{2}=0 \%, \mathrm{P}<0.00001\right)$ and sedation duration $\left(\mathrm{MD}=17.52,95 \%\right.$ CI $\left.[10.3,24.71], \mathrm{I}^{2}=0 \%, \mathrm{P}<0.05\right)$, which included 1052, 710 and 727 children for this analysis, respectively. Compared to diazepam, there was no significant difference in success rate of sedation $(\mathrm{RR}=0.93,95 \% \mathrm{CI}[0.80,1.08]$, $\mathrm{I}^{2}=52 \%, \mathrm{P}=0.32$ ), which included 230 children for this analysis. Compared to dexmedetomidine, there was no significant difference in the success rate of sedation $(R R=0.92,95 \%$ CI $\left.[0.80,1.06], \mathrm{I}^{2}=48 \%, \mathrm{P}=0.27\right)$ and sedation latency $(\mathrm{RR}=-1.09,95 \%$ CI $[-2.45,0.26]$, $\mathrm{I}^{2}=26 \%, \mathrm{P}=0.11$ ), which included 512 and 371 children for this analysis, respectively. Compared to barbiturates, there was no significant difference in the success rate of sedation $\left(\mathrm{RR}=1.03,95 \% \mathrm{CI}[0.94,1.13], \mathrm{I}^{2}=50 \%, \mathrm{P}=0.58\right)$ and sedation duration $(\mathrm{MD}=-0.72,95 \%$ CI $\left.[-1.78,0.34], \mathrm{I}^{2}=38 \%, \mathrm{P}=0.18\right)$, which included 749 and 210 children for this analysis, respectively.

Conclusions: From the extrapolation of the existing literature, $\mathrm{CH}$ oral solution is an appropriate effective alternative for sedation in pediatrics.

Keywords: chloral hydrate, efficacy, sedation, children, meta-analysis

\section{Introduction}

Sedation is defined as a drug-induced depression of consciousness, which is a continuum from wakefulness to anesthesia. ${ }^{1}$ It assists in reducing anxiety, providing
Correspondence: Lingli Zhang

West China Second University Hospital, Sichuan University, No.20, Third Section, Renmin Nan Lu, Chengdu, Sichuan 6I004I, People's Republic of China Fax +862885503025

Email zhanglingli@scu.edu.cn 
pain control and reducing movement of the patient when undergoing a procedure. Children can easily become anxious during medical procedures. Pain and anxiety sometimes make the procedure more difficult to perform for the medical staff, due to movement or a lack of cooperation from the patient. ${ }^{2}$ As a result, children frequently require sedation to undergo examination or diagnostic imaging.

Sedative medications are used to reduce pain and anxiety. They can be injected directly into the bloodstream, injected into muscle tissue, given as a nasal spray, or swallowed as a tablet or solution. Chloral hydrate $(\mathrm{CH})$ is a central nervous system depressant and is one of the oldest sedatives (discovered in 1832). It is well absorbed orally as well as rectally and rapidly metabolized into the active metabolite trichloroethyl alcohol, which is responsible for its sedative and hypnotic effects. ${ }^{3}$ It is one of the most frequently used sedative agents in pediatric ophthalmology, dentistry, radiology and so on. NICE 2010 guideline recommends that $\mathrm{CH}$ is considered for children under $15 \mathrm{~kg}$ who are unable to tolerate a painless procedure (for example, during diagnostic imaging), which have a wide margin of safety. ${ }^{4}$ American College of Emergency Physicians 2008 guideline recommends that $\mathrm{CH}$ may be used to provide effective procedural sedation in pediatric patients undergoing painless diagnostic studies. However, children receiving $\mathrm{CH}$ should be properly monitored and managed by appropriately trained personnel due to the risk of respiratory depression and hypoxia. ${ }^{5}$

Contemporarily, $\mathrm{CH}$ has entered the pharmaceutical market in Japan, Australia, England and Switzerland, but it is only widely used as a hospital preparation in China. Meanwhile, there is no systematic review of the efficacy of $\mathrm{CH}$ for sedation in pediatrics. Henceforth, this review aims at systematically evaluating the efficacy of $\mathrm{CH}$ oral solution in pediatrics for sedation to provide evidence for health professionals who prescribe $\mathrm{CH}$, as well as pharmaceutical research and development.

\section{Materials and methods}

\section{Search strategy}

Our research comprises three English electronic databases (PubMed, EMBase, Cochrane Library) and four Chinese electronic databases (China National Knowledge Infrastructure, WanFang Database, Chinese Biomedical Literature Database, VIP Database for Chinese Technical
Periodicals). Three clinical trial registry platforms were used to find additional studies, including ClinicalTrials.gov, the World Health Organization Clinical Trials Registry Platform and Cochrane Central Registry of Controlled Trials.

The search strategy was specific for each database and included a combination of the medical subject headings and free text terms for ("chloral hydrate" or "somnos" or "nycton" or "dormal") and ("child" or "newborn" or "infant" or "neonate" or "toddler" or "teenager" or "adolescent" or "pediatric"). We looked for additional studies in reference lists of selected articles and contacted with authors for unclear information. The deadline of all retrieval was September 2018.

This protocol was registered with the international prospective register of systematic review: CRD42018108967.

\section{Inclusion criteria}

The following studies were included: (1) Participants: pediatric patients (0-18 years) needed sedation before diagnostic procedures, which were classified according to the International Conference on Harmonisation of Technical Requirements for Registration of Pharmaceuticals for Human Use Criteria: preterm newborn infants, term newborn infants (birth to 27 days), infants and toddlers (28 days to 23 months), children (24 months to 11 years) and adolescents $(12-18 \text { years })^{6}$. (2) Intervention: chloral hydrate oral solution. (3) Comparison: placebo, no intervention or other sedative hypnotics. ${ }^{7}$ (4) Outcomes: success rate of sedation, sedation latency, sedation duration. ${ }^{8}(5)$ Type of study: randomized controlled trial (RCT).

\section{Exclusion criteria}

The following studies were excluded: (1) Studies with incomplete or missing information. (2) Not Chinese or English literature. (3) Comparative study of different routes of administration of chloral hydrate.

\section{Data extraction}

Data were extracted from all included studies. Extracted information included: study information (author, published time of included studies, country), method (study design, information of quality evaluation), intervention (sample size, medicine, administration route, dose), outcomes (success rate of sedations, sedation latency, sedation duration).

Two independent reviewers screened all the titles and abstracts to determine potential eligible articles. They independently applied the eligibility criteria to perform 
the final selection. When discrepancies occurred between both reviewers regarding the inclusion of the articles, they would discuss and identify the reasons to either include or exclude the articles and then make the final decision. If they could not reach an agreement, the final decision would be based on a third reviewer.

\section{Risk of bias assessment}

We used the Cochrane risk of bias tool for RCT studies.

\section{Data analysis}

Meta-analysis was conducted with RevMan 5.3. The data were pooled and expressed as relative risks (RR) or Mean Difference (MD) with 95\% confidence interval (CI). Heterogeneity assessment was done by I-squared $\left(\mathrm{I}^{2}\right)$ statistics. A fixed effects model was initially conducted. If significant heterogeneity existed among trials $\left(\mathrm{I}^{2}>50 \%\right)$, potential sources of heterogeneity were considered, and where appropriate a random effects model was used.

\section{Results}

\section{Characteristics of the included studies}

A total of 2045 records were identified for initial screening and 24 eligible studies published between 2000 and 2017 were included in this meta-analysis (Figure 1). A total of 3564 children were enrolled in this study. The dose range of $\mathrm{CH}$ oral solution is $25-100 \mathrm{mg} / \mathrm{kg}$ (Table 1 ).

\section{Quality assessment}

According to Cochrane risk of bias estimation, the seven items including random sequence generation, allocation concealment, blinding of participants and personnel, blinding of outcome assessment, incomplete outcome data, selective reporting and other bias of these were evaluated. $54.2 \%$ of studies $(13 / 24)$ used an adequate method of random sequence generation, such as using a random number table or a computer-generated random number table. Only one study mentioned allocation concealment. $25 \%$ of studies $(6 / 24)$ performed on blinding of participants and personnel, such as using computer distribution in the center. $66.7 \%$ of studies $(16 / 24)$ reported complete outcomes. $62.5 \%$ of studies $(15 / 24)$ reported no selective reporting with checking protocols. Blinding of outcome assessment and other bias were vague in the majority of trials (Figure 2).

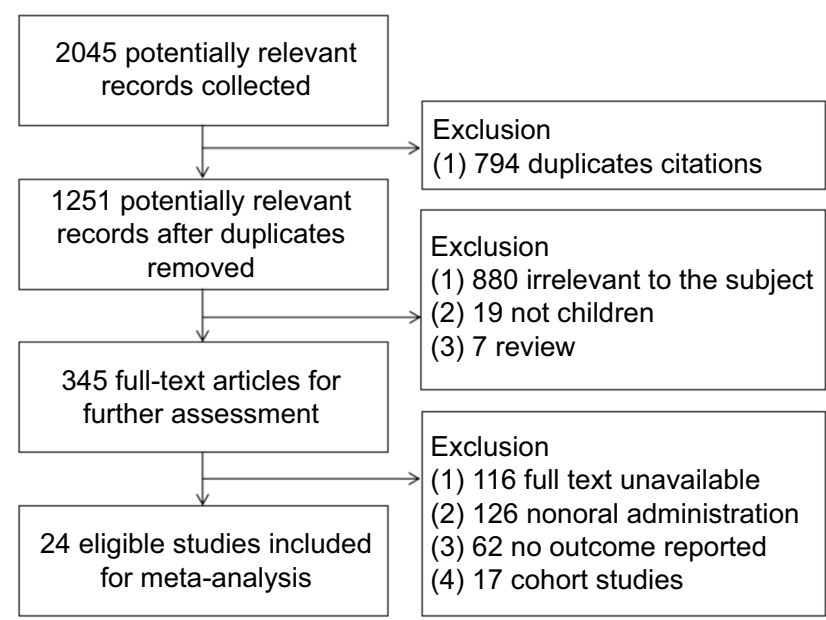

Figure I Flow diagram of selecting study.

\section{Outcomes}

\section{$\mathrm{CH}$ versus placebo}

Success rate of sedation

Among the 24 RCT studies, 2 studies with 477 children contributed to this analysis. Compared to placebo group, the success rate of sedation increased significantly in $\mathrm{CH}$ group when used for painless and painful procedure $[\mathrm{RR}=4.15,95 \%$ CI $(1.21,14.24), \mathrm{P}=0.02 ; \mathrm{RR}=1.28,95 \%$ CI $(1.17,1.40), \mathrm{P}<0.01] .^{13,28}$

\section{$\mathrm{CH}$ versus midazolam}

Success rate of sedation

Among the 24 RCT studies, 8 studies with 1052 children contributed to this analysis. ${ }^{8,9,14,18,21-23,26}$ Before sensitivity analysis, three studies had significant heterogeneity., 98,26 After sensitivity analysis, compared to midazolam group, the success rate of sedation increased significantly in $\mathrm{CH}$ group with no heterogeneity $[\mathrm{RR}=1.63$, 95\% CI $(1.48$, 1.79), $\left.\mathrm{I}^{2}=0 \%, \mathrm{P}<0.00001\right]$ (Figure 3). ${ }^{8,14,21-23}$

\section{Group \\ Sedation latency}

Among the 24 RCT studies, 5 studies with 710 children contributed to this analysis. ${ }^{8,14,18,21,26}$ Before sensitivity analysis, two subgroups had significant heterogeneity. ${ }^{8,26}$ After sensitivity analysis, the sedation latency in $\mathrm{CH}$ group was longer than in midazolam group with no heterogeneity $[\mathrm{MD}=13.29$, 95\% CI (11.42, 15.16), $\left.\mathrm{I}^{2}=0 \%, \mathrm{P}<0.00001\right]$ (Figure 4). ${ }^{14,18,21}$

\section{Sedation duration}

Among the 24 RCT studies, 4 studies with 727 children contributed to this analysis. ${ }^{8,21,23,26}$ Before sensitivity analysis, 


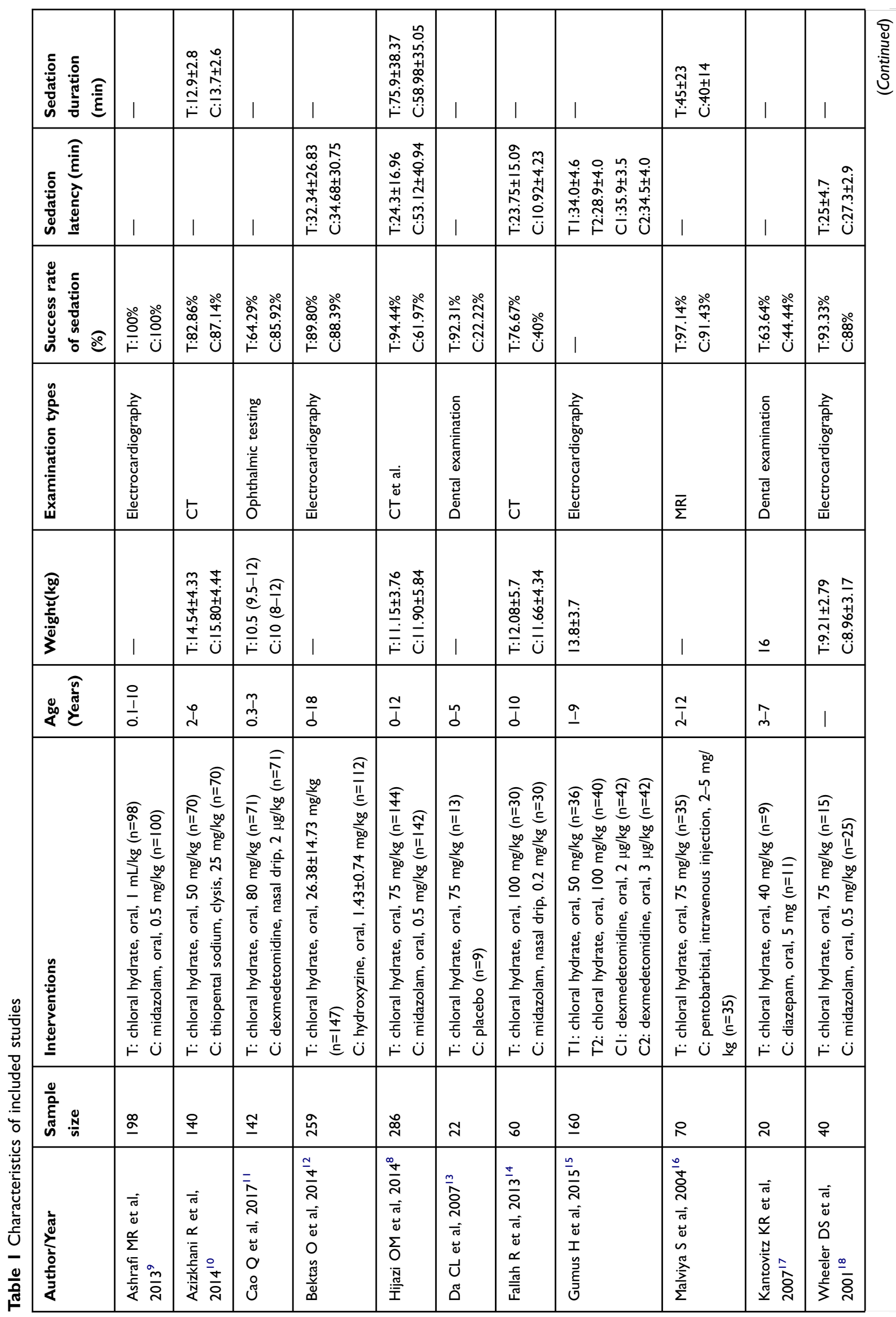




\begin{tabular}{|c|c|c|c|c|c|c|c|c|c|c|}
\hline 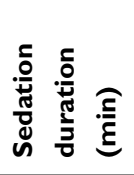 & I & 1 & 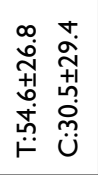 & | & 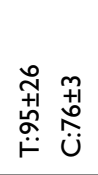 & I & 1 & 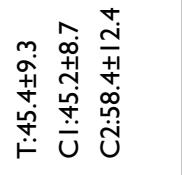 & & 1 \\
\hline 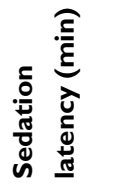 & 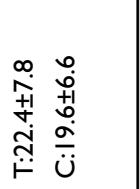 & 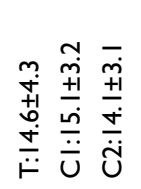 & 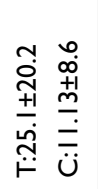 & I & I & 1 & 1 & 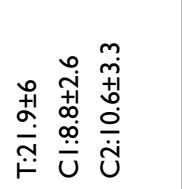 & 1 & | \\
\hline 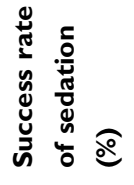 & 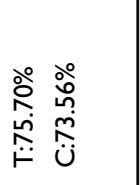 & 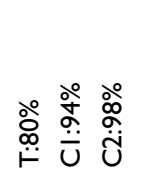 & 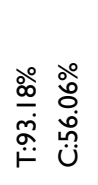 & 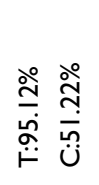 & 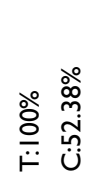 & 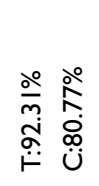 & I & 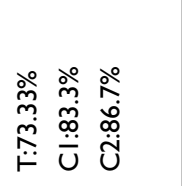 & | & 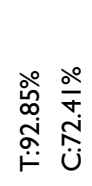 \\
\hline 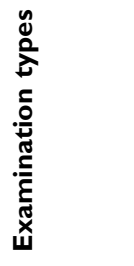 & 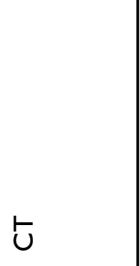 & $\overline{\bar{\Sigma}}$ & 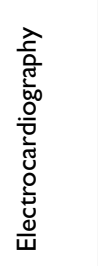 & 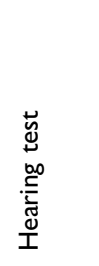 & $\overline{\underline{\Sigma}}$ & 1 & 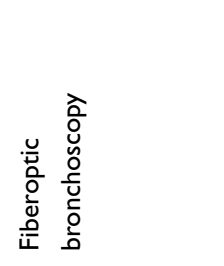 & 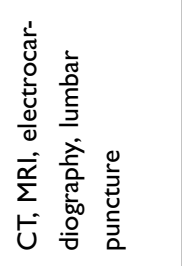 & 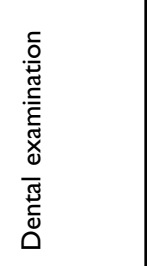 & 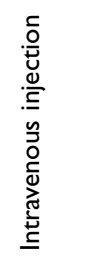 \\
\hline 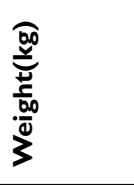 & 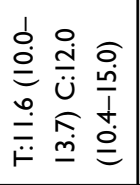 & 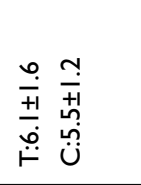 & 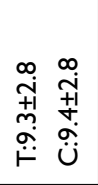 & 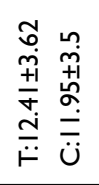 & 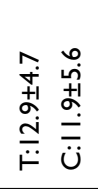 & I & $\begin{array}{l}\stackrel{\sim}{0} \\
\stackrel{m}{m}\end{array}$ & I & 1 & I \\
\hline 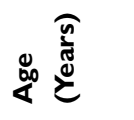 & $\underline{I}$ & $\begin{array}{l}\text { no } \\
\vdots \\
0\end{array}$ & $\begin{array}{l}\hat{n} \\
\hat{\alpha} \\
\alpha\end{array}$ & $\underline{I}$ & $\frac{\infty}{1}$ & $\begin{array}{l}1 \\
\infty \\
0 \\
0\end{array}$ & $\frac{\pi}{d}$ & t & $\frac{1}{0}$ & $\begin{array}{l}1 \\
0 \\
0 \\
0\end{array}$ \\
\hline 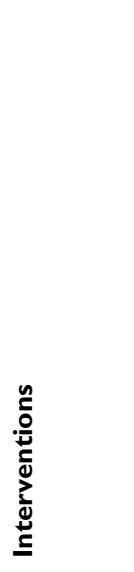 & 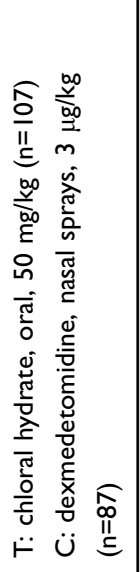 & 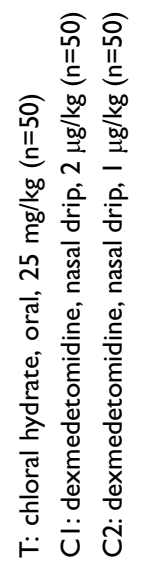 & 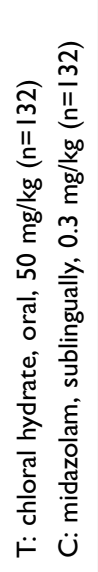 & 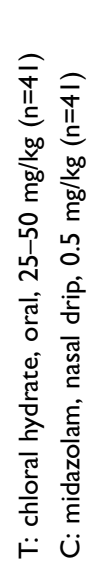 & 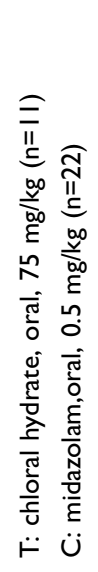 & 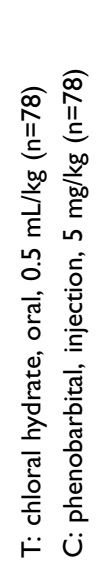 & 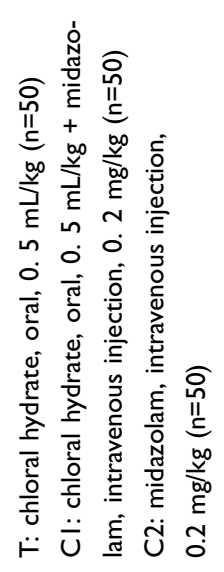 & 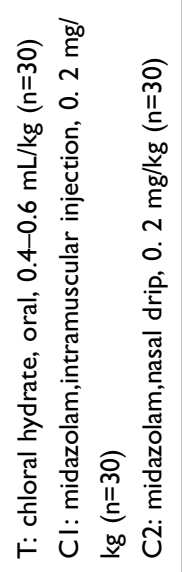 & 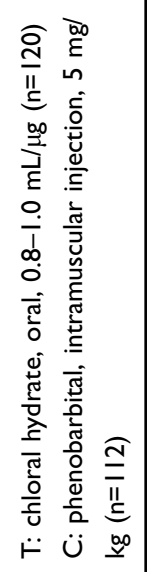 & 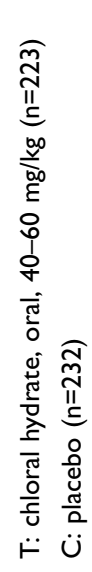 \\
\hline $\begin{array}{l}\frac{0}{0} \\
\text { हैँ } \\
\text { जू }\end{array}$ & $\stackrel{\Xi}{\sigma}$ & 요 & $\underset{\sim}{+}$ & ను & $\stackrel{m}{m}$ & $\stackrel{\text { ㅇ }}{2}$ & 요 & ㅇ & $\stackrel{\widetilde{\sim}}{\sim}$ & $\ddot{\mathscr{g}}$ \\
\hline 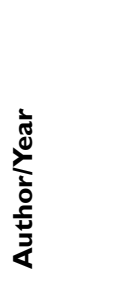 & 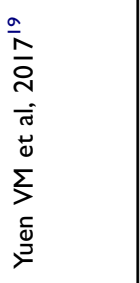 & 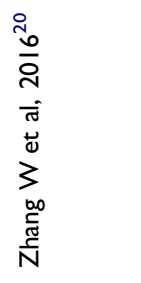 & 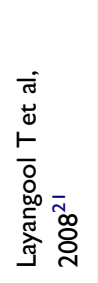 & 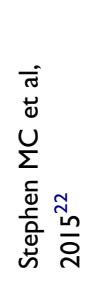 & 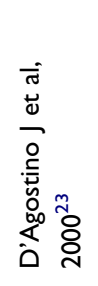 & 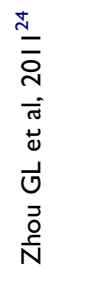 & 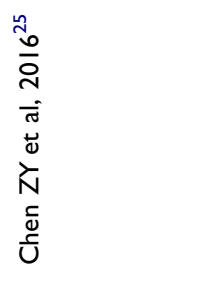 & 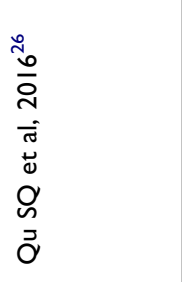 & 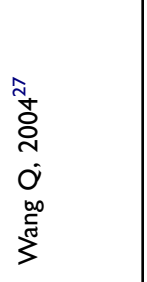 & 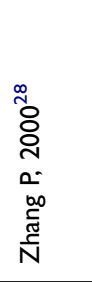 \\
\hline
\end{tabular}




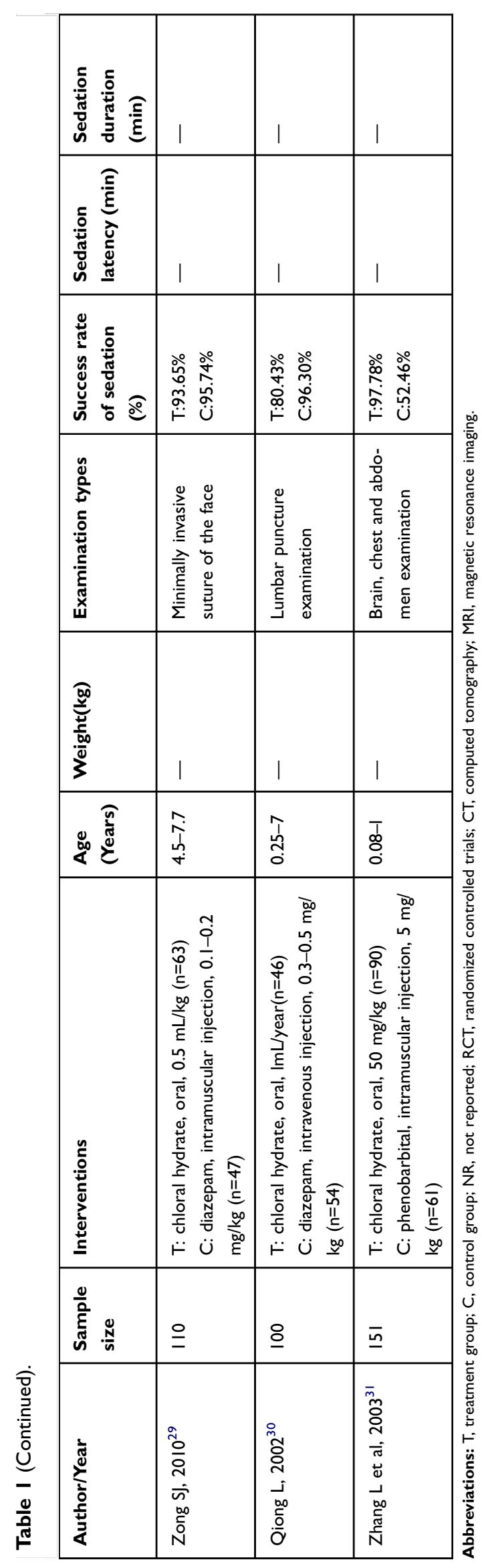




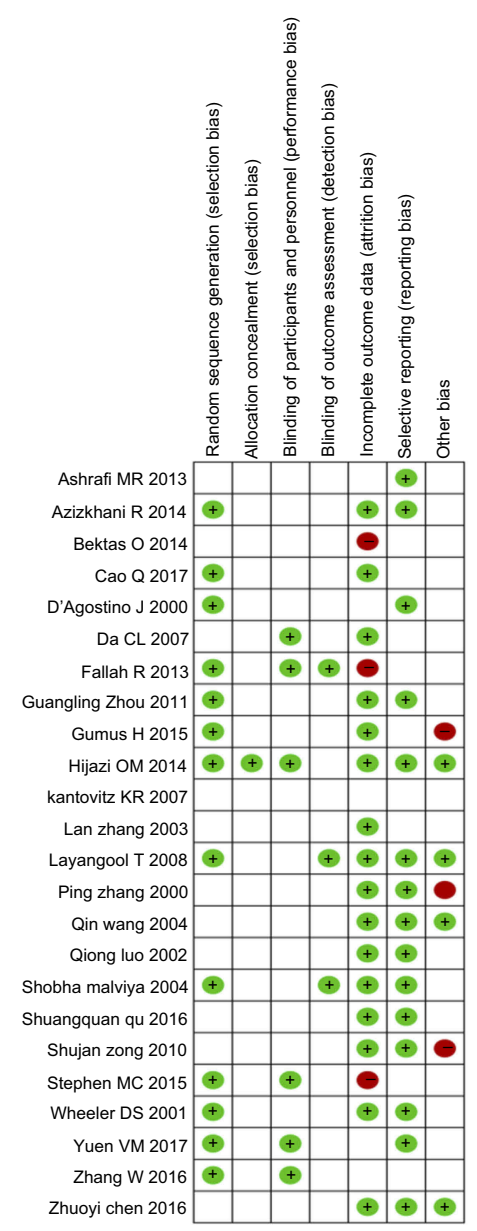

Figure 2 Quality assessment of included studies.

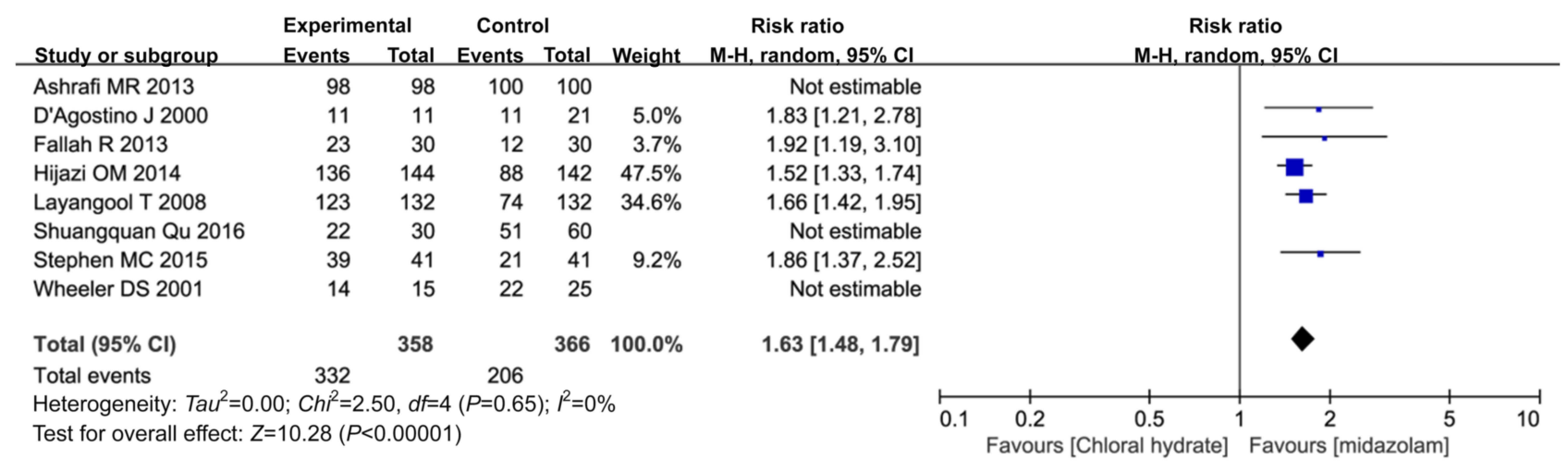

Figure 3 The success rate of sedation between chloral hydrate group and midazolam.

two subgroups had substantial heterogeneity. ${ }^{21,26}$ After sensitivity analysis, the sedation duration in $\mathrm{CH}$ group was longer than in midazolam group with no heterogeneity $[\mathrm{MD}=17.52$, $95 \%$ CI $\left.(10.3,24.71), I^{2}=0 \%, P<0.05\right]$ (Figure 5). ${ }^{8,23}$
$\mathrm{CH}$ versus diazepam Success rate of sedation

Among the 24 RCT studies, 3 studies with 230 children contributed to this analysis. ${ }^{17,29,30}$ There was no significant 


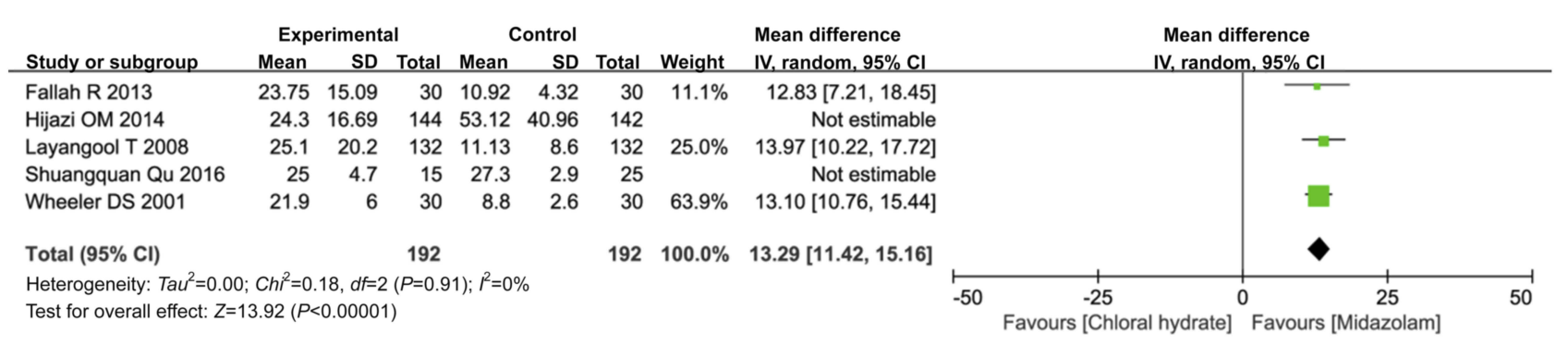

Figure 4 The sedation latency between chloral hydrate group and midazolam group.

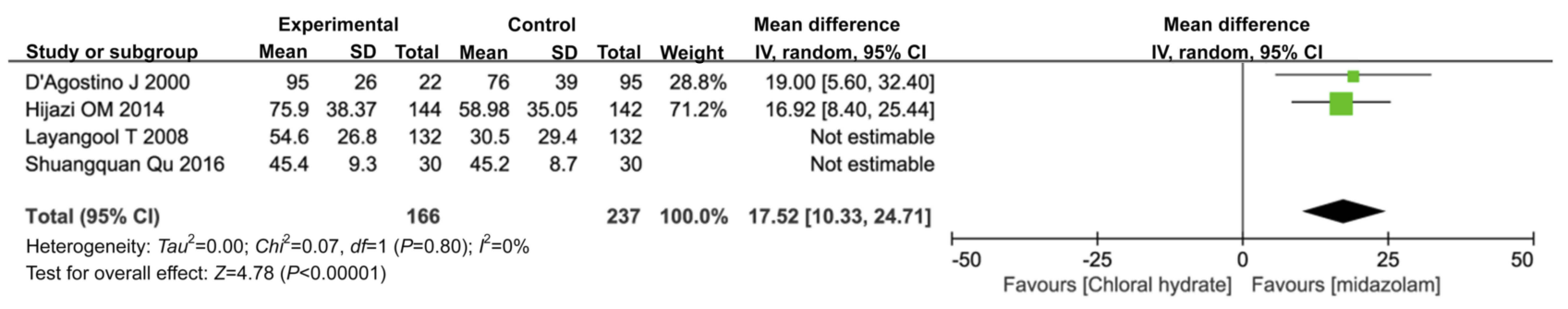

Figure $\mathbf{5}$ The sedation duration between chloral hydrate group and midazolam group.

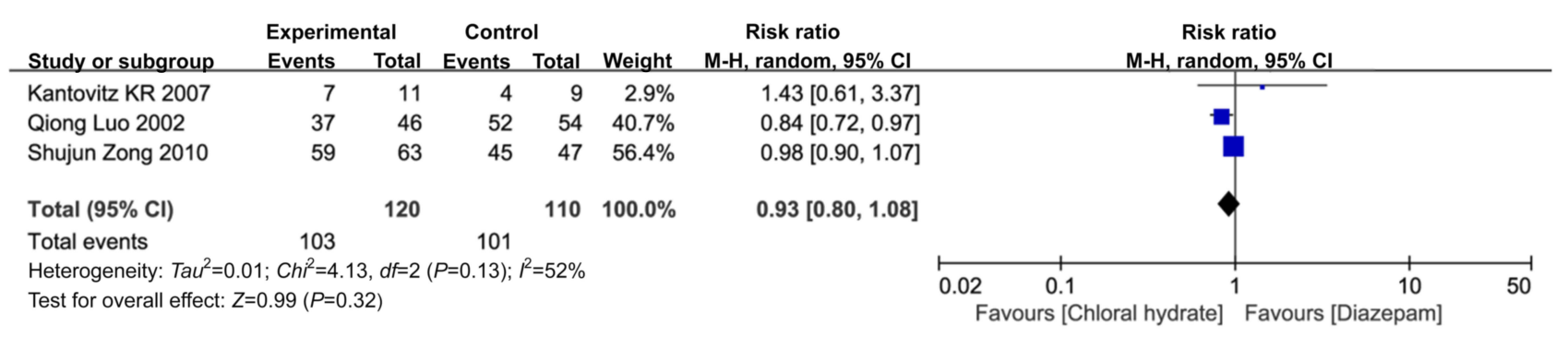

Figure 6 The success rate of sedation between chloral hydrate group and diazepam group.

difference in success rate of sedation between $\mathrm{CH}$ group and diazepam group $[\mathrm{RR}=0.93,95 \% \mathrm{CI}(0.80,1.08)$, $\left.\mathrm{I}^{2}=52 \%, \mathrm{P}=0.32\right]$ (Figure 6).

\section{$\mathrm{CH}$ versus dexmedetomidine}

\section{Success rate of sedation}

Among the 24 RCT studies, 4 studies with 512 children contributed to this analysis. ${ }^{11,15,19,20}$ Before sensitivity analysis, one subgroup had significant heterogeneity. ${ }^{11}$ After sensitivity analysis, there was no significant difference in success rate of sedation between $\mathrm{CH}$ group and dexmedetomidine group $\left[\mathrm{RR}=0.92,95 \% \mathrm{CI}(0.80,1.06), \mathrm{I}^{2}=48 \%, \mathrm{P}=0.27\right]$ (Figure 7).

\section{Sedation latency}

Among the 24 RCT studies, 3 studies with 371 children contributed to this analysis. ${ }^{15,19,20}$ Before sensitivity analysis, one subgroup had significant heterogeneity. ${ }^{19}$ After sensitivity analysis, there was no significant difference in sedation latency between $\mathrm{CH}$ group and dexmedetomidine group $\left[\mathrm{RR}=-1.09,95 \% \mathrm{CI}(-2.45,0.26), \mathrm{I}^{2}=26 \%, \mathrm{P}=0.11\right]$ with no heterogeneity (Figure 8). ${ }^{15,20}$

\section{$\mathrm{CH}$ versus barbiturates}

\section{Success rate of sedation}

Among the 24 RCT studies, 5 studies with 749 children contributed to this analysis. ${ }^{10,16,24,27,31}$ Before sensitivity analysis, one subgroup had significant heterogeneity. ${ }^{31}$ After sensitivity analysis, there was no significant difference in success rate of sedation between $\mathrm{CH}$ group and barbiturates group $[\mathrm{RR}=1.03,95 \%$ CI $(0.94,1.13)$, $\left.\mathrm{I}^{2}=50 \%, P=0.58\right]$ (Figure 9).

\section{Group}

\section{Sedation duration}

Among the 24 RCT studies, 2 studies with 210 children contributed to this analysis. ${ }^{10,16}$ There was no significant 


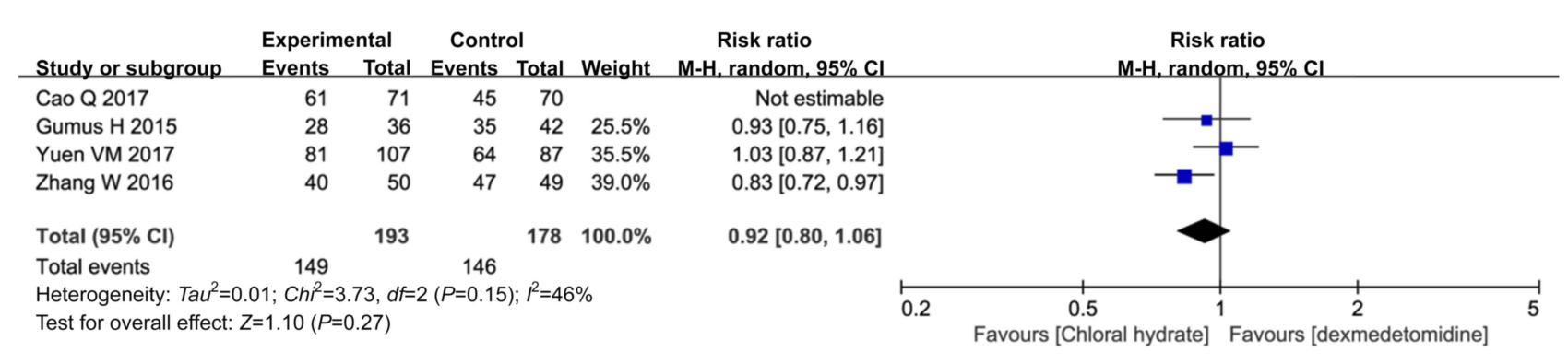

Figure 7 The success rate of sedation between chloral hydrate group and dexmedetomidine group.

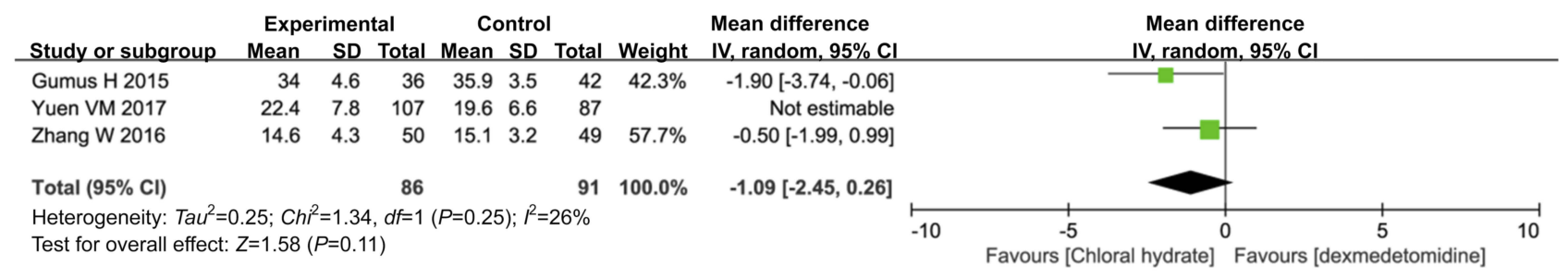

Figure 8 The sedation latency between chloral hydrate group and dexmedetomidine group.

difference in sedation duration in $\mathrm{CH}$ group and barbiturates group $\left[\mathrm{MD}=-0.72,95 \% \mathrm{CI}(-1.78,0.34), \mathrm{I}^{2}=38 \%, \mathrm{P}=0.18\right]$ (Figure 10).

\section{Discussion}

Sedating children for diagnostic and therapeutic procedures continues to pose challenges. ${ }^{8}$ The methodology of sedation is needed to decrease patients' anxiety, movement and radiation exposure, which ultimately elevate the quality of procedural outcomes. Commonly used sedative hypnotics including benzodiazepines (such as midazolam, diazepam, triazolam), aldehydes (such as $\mathrm{CH}$ ), barbiturates (such as thiopental), imidazole pyridine derivatives (such as zolpidem), benzene ring piperidine derivatives (ketamine) are prevalently prescribed in the current clinical diagnostic and therapeutic procedures. Moreover, within these categories of sedatives, $\mathrm{CH}$, midazolam, dexmedetomidine are recommended for sedation in children in the guideline. $^{4,5}$

The present study was a meta-analysis to evaluate the efficacy of $\mathrm{CH}$ oral solution for sedation in pediatrics. Based on the existing evidence from $24 \mathrm{RCTs}$, the analysis indicated that the sedative effect of $\mathrm{CH}$ was better than midazolam, which was consistent with the results of Wilson ME et al. ${ }^{1}$ Additionally, there was no significant difference between the $\mathrm{CH}$ and diazepam, dexmedetomidine, barbiturates in the success rate of sedation. Meanwhile, children aged 0-18 were with a prospering success rate of sedation that ranges from $63.61 \%$ to $100 \%$ in this study. Consequently, the sedation success rate of hearing test, electrocardiography, MRI, ophthalmic testing, lumbar puncture examination, CT and dental examination with a significant expression were $95.12 \%$,

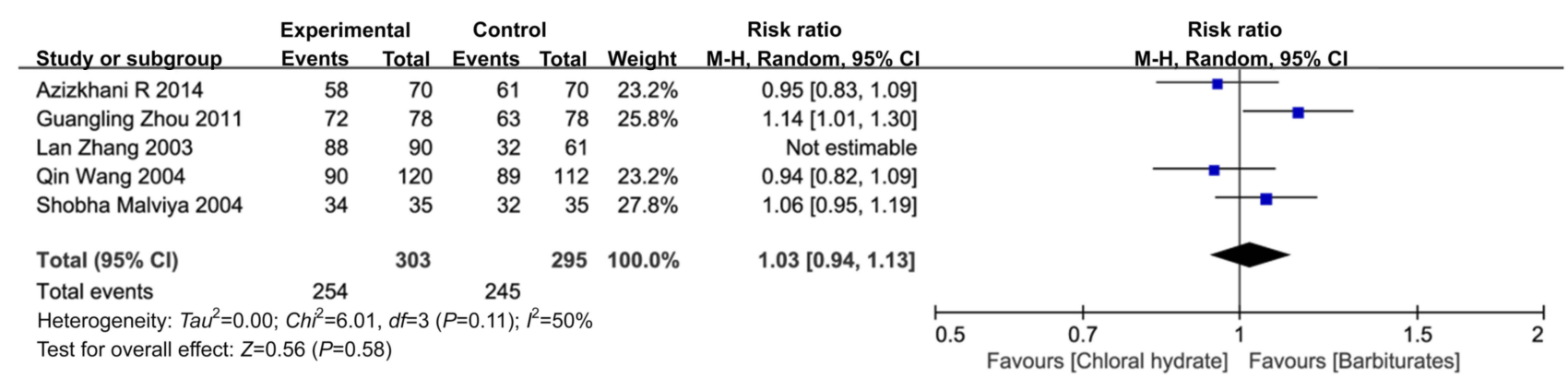

Figure 9 The success rate of sedation between chloral hydrate group versus barbiturates. 


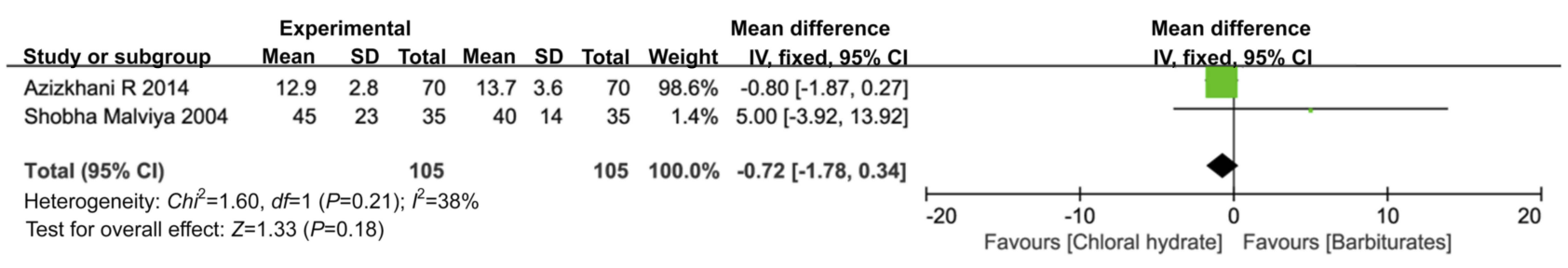

Figure 10 The sedation duration between chloral hydrate group versus barbiturates.

$93.62 \%, \quad 88.54 \%, \quad 85.92 \%, \quad 80.43 \%, \quad 78.26 \%, \quad 76.05 \%$, respectively.

From the existing secondary evidence, $\mathrm{CH}$ recommended by the NICE 2010 guideline for children under $15 \mathrm{~kg}$ who are unable to tolerate a painless procedure had a wide margin of safety. ${ }^{4}$ The American College of Emergency Physicians 2008 guideline suggested that $\mathrm{CH}$ could be used to provide effective procedural sedation in pediatric patients undergoing painless diagnostic studies (level A recommendation). ${ }^{5}$ Two experts' consensus recommended $\mathrm{CH}$ could be used for sedation before noninvasive procedure and imaging examination in China. ${ }^{32,33}$ The systematic review of Asimina Mataftsi et al indicated that despite the paucity of high-quality evidence, the existing literature suggested that the use of $\mathrm{CH}$ for procedural sedation in children appears to be an effective alternative to general anesthesia. ${ }^{34}$ This is due to its ability to be safely administered in the hospital setting with appropriate monitoring and vigilance for intervention. ${ }^{16}$ Therefore, these above evidences suggested that $\mathrm{CH}$ oral solution could be used for sedation in pediatrics.

We also recognized the limitations of this study. Firstly, only $25 \%$ of studies $(6 / 24)$ were performed on blinding of participants and personnel assessment. Blinding of outcome assessment, allocation concealment and other bias were ambiguous in the majority of trials. These results indicated the overall quality of the included literature was not satisfactory. Due to only 6 studies being blinded, we did sensitivity analysis of the main outcome indicator of success rate of sedation and the results indicated no differences in the success rate of sedation between $\mathrm{CH}$ and midazolam or dexmedetomidine. Furthermore, before sensitivity analysis, some studies had compelling levels of heterogeneity, which might be caused by the quality of the studies, the dose of the treatment and control group, the sample size, the age of the child, the type of examination, etc. Thirdly, this study only included Chinese or English literature and there might be varying degrees of language bias. Although this systematic review and meta-analysis retrieved the mainstream databases, there might still be cases of missed detection. Additionally, this study only reported the efficacy of $\mathrm{CH}$ oral solution for sedation in pediatrics; the safety of $\mathrm{CH}$ oral solution for sedation in pediatrics would be reported in another manuscript.

\section{Conclusion}

From the extrapolation of the existing literature, $\mathrm{CH}$ oral solution is an appropriate effective alternative for sedation in pediatrics.

\section{Acknowledgments}

We thank Group of People with Highest Risk of Drug Exposure of International Network for the Rational Use of Drugs and program for Yangtze River Scholars and Innovative Research Team (No. IRT0935).

\section{Author contributions}

Zhe Chen conducted data analysis and wrote the manuscript. Mao Lin and Zongyao Huang retrieved and screened the literature, as well as extracted data. Linan Zeng, Liang Huang and Dan Yu established inclusion and exclusion criteria, as well as outcome indicators. Lingli Zhang designed the study and resolved the problems in research process. All authors contributed to data analysis, drafting and revising the article, gave final approval of the version to be published, and agreed to be accountable for all aspects of the work.

\section{Disclosure}

The authors report no conflicts of interest in this work.

\section{References}

1. Wilson ME, Karaoui M, Djasim LA, Edward DP, Shamrani MA, Friedman SD. The safety and efficacy of chloral hydrate sedation for pediatric ophthalmic procedures: a retrospective review. $J$ Pediatr Ophthalmol Strabismus. 2014;3(51):154-159. doi:10.3928/0191391320140311-01

2. Conway A, Rolley J, Sutherland JR. Midazolam for sedation before procedures. Cochrane Libary. 2016;4:1. 
3. Fong CY, Tay CG, Ong LC, et al. Chloral hydrate as a sedating agent for neurodiagnostic procedures in children. Cochrane Libary. 2015;7:1-5.

4. National Institute for Health and Care Excellence. Sedation in under 19s: Using Sedation for Diagnostic and Therapeutic Procedures. UK; 2010:17-18

5. Mace SE, Brown LA, Francis L, et al. Clinical policy: critical issues in the sedation of pediatric patients in the emergency department. $J$ Emerg Nurs. 2008;34(3):e33. doi:10.1016/j.jen.2008.04.018

6. The International Conference on Harmonization of Technical Requirements for Registration of Pharmaceuticals for Human Use. Guidance for industry E11 clinical investigation of medicinal products in the pediatric population; 2000. http://www.fda.gov/cder/gui dance/index.htm. Accessed January 9, 2017.

7. Higgins J, Green S. Cochrane Handbook for Systematic Reviews of Interventions. Chichester, UK: The Cochrane Library, John Wiley \& Sons; 2011.

8. Hijazi OM, Ahmed AE, Anazi JA, et al. Chloral hydrate versus midazolam as sedative agents for diagnostic procedures in children. Saudi Med J. 2014;35(2):123-131.

9. Ashrafi MR, Malamiri RA, Zamani GR, et al. Sleep inducing for EEG recording in children: a comparison between oral midazolam and chloral hydrate. Iran J Child Neurol. 2013;7(1):15.

10. Azizkhani R, Kanani S, Sharifi A, et al. Oral chloral hydrate compare with rectal thiopental in pediatric procedural sedation and analgesia; a randomized ciinical trial. Emergency. 2014;2(2):85-89.

11. Cao Q, Lin Y, Xie Z, et al. Comparison of sedation by intranasal dexmedetomidine and oral chloral hydrate for pediatric ophthalmic examination. Paediatr Anaesth. 2017;27:6. doi:10.1111/pan.13148

12. Bektas O, Arıca B, Teber S, et al. Chloral hydrate and/or hydroxyzine for sedation in pediatric EEG recording. Brain Dev. 2014;36(2):130 136. doi:10.1016/j.braindev.2013.03.002

13. Da LC, Da PC, Lima AR. A randomized double-blinded trial of chloral hydrate with or without hydroxyzine versus placebo for pediatric dental sedation. Braz Dent J. 2007;18(4):334-340.

14. Fallah R, Nakhaei MHA, Behdad S, et al. Oral chloral hydrate vs. intranasal midazolam for sedation during computerized tomography. Indian Pediatr. 2013;50(2):233-235.

15. Gumus H, Bayram AK, Poyrazoglu HG, et al. Comparison of effects of different dexmedetomidine and chloral hydrate doses used in sedation on electroencephalography in pediatric patients. J Child Neurol. 2015;30(8):983-988. doi:10.1177/0883073814549582

16. Malviya S, Voepel-Lewis T, Tait AR, et al. Pentobarbital vs chloral hydrate for sedation of children undergoing MRI: efficacy and recovery characteristics. Paediatr Anaesth. 2004;14(7):52089-52595. doi:10.1111/j.1460-9592.2004.01243.x

17. Kantovitz KR, Puppinrontani RM, Gaviao MB. Sedative effect of oral diazepam and chloral hydrate in the dental treatment of children. J Indian Soc Pedod Prev Dent. 2007;25(2):69. doi:10.4103/09704388.33451

18. Wheeler DS, Jensen RA, Poss WB. A randomized, blinded comparison of chloral hydrate and midazolam sedation in children undergoing echocardiography. Clin Pediatr. 2001;40(7):381-387. doi:10.1177/000992280104000704

Drug Design, Development and Therapy

\section{Publish your work in this journal}

Drug Design, Development and Therapy is an international, peerreviewed open-access journal that spans the spectrum of drug design and development through to clinical applications. Clinical outcomes, patient safety, and programs for the development and effective, safe, and sustained use of medicines are a feature of the journal, which has also
19. Yuen VM, Li BL, Cheuk DK, et al. A randomised controlled trial of oral chloral hydrate vs. intranasal dexmedetomidine before computerised tomography in children. Anaesthesia. 2017;72(10):299. doi:10.1111/anae.13981

20. Zhang W, Wang Z, Song X, et al. Comparison of rescue techniques for failed chloral hydrate sedation for magnetic resonance imaging scans-additional chloral hydrate vs intranasal dexmedetomidine. Paediatr Anaesth. 2016;26(3):273-279. doi:10.1111/pan.12824

21. Layangool T, Sangtawesin C, Kirawittaya T, et al. A comparison of oral chloral hydrate and sublingual midazolam sedation for echocardiogram in children. $J$ Med Assoc Thai. 2008;91(Suppl 3):S45.

22. Stephen MC, Mathew J, Varghese AM, et al. A randomized controlled trial comparing intranasal midazolam and chloral hydrate for procedural sedation in children. Otolaryngol Head Neck Surg. 2015;153(6):1042. doi:10.1177/0194599815599381

23. D'Agostino J, Terndrup TE. Chloral hydrate versus midazolam for sedation of children for neuroimaging: a randomized clinical trial. Pediatr Emerg Care. 2000;16(1):1-4.

24. Zhou GL, Gao YX, Qu SY. Chloral hydrate versus phenobarbita for sedation of infants. Chin J Mod Nurs. 2011;17(11):1290-1291.

25. Chen ZY, Lin CX, Chen JL. Midazolam with chloral hydrate for sedation of children for fiberoptic bronchoscopy. Guangdong Med Journal. 2016;37(21):3278-3279.

26. Qu SQ, Wang RK, Xiao T, et al. Multiple routes of administration on the sedation of pediatric outpatient department. J Pediatr Pharm. 2016;7:17-19.

27. Wang Q. Effect of chloral hydrate for controlling child activity on dental clinics. Clin Educ Gen Pract. 2004;2(4):218-219.

28. Zhang P. Efficacy of chloral hydrate for sedation in children. Heilong Jiang J Nur. 2000;4:3.

29. Zong SJ. Midazolam with chloral hydrate with diazepam for sedation of children for facial debridement suture. Today Nurse. 2010;12:42-43.

30. Qiong L. Effect of chloral hydrate or tranquil for sedation before lumbar puncture in children. Chongqing Med. 2002;31(5):415-416.

31. Zhang L, Xing XL, Qin DJ. The sedative effect comparing and sedation method selection during CT scan for baby. J Med Imaging. 2003;13(6):446.

32. Shangguan WN, Yin N, Zuo YX, et al. Expert consensus of surgery outdoor anesthesia/sedation in pediatric. 2017. http://www.csaol.cn/a/ xuehuigongzuo/linchuangzhinan/2017/1213/13722.htmL. Accessed July $07,2019$.

33. Emergency Group of Pediatrics Branch in Chinese Medical Association, Pediatric Group of Emergency Branch in Chinese Medical Association, Pediatric Professional Committee of Critical Care Physicians Branch in Chinese Medical Doctors Association. Expert consensus on analgesia and sedation for children in intensive care unit. Chin J Pediatr. 2014;3(52):189-192.

34. Mataftsi A, Malamaki P, Prousali E, et al. Safety and efficacy of chloral hydrate for procedural sedation in paediatric ophthalmology: a systematic review and meta-analysis. $\mathrm{Br} J$ Ophthalmol. 2017;5(10):189. been accepted for indexing on PubMed Central. The manuscript management system is completely online and includes a very quick and fair peer-review system, which is all easy to use. Visit http://www. dovepress.com/testimonials.php to read real quotes from published authors. 